\title{
2467. Vibroactivity analysis of a dual fuel diesel engine based on the knock sensor signal and measuring pressure in the combustion chamber
}

\author{
Krzysztof Szczurowski ${ }^{1}$, Lukasz Kurkus ${ }^{2}$, Damian Walczak ${ }^{3}$, Lukasz Zieliński ${ }^{4}$ \\ Warsaw University of Technology Institute of Vehicles, Warsaw, Poland \\ ${ }^{4}$ Corresponding author \\ E-mail: ${ }^{1} k s z c z u r @ s i m r . p w . e d u . p l,{ }^{2} l u k a s z . k u r k u s @ g m a i l . c o m,{ }^{3} d . w a l c z a k @ m e c h a t r o n i k a . n e t . p l$, \\ 4lukaszzielinski@hotmail.com
}

Received 7 September 2016; received in revised form 13 February 2017; accepted 12 March 2017

DOI https://doi.org/10.21595/jve.2017.17713

Check for updates

\begin{abstract}
A study conducted by a team of authors attempts to identify the occurrence of knocking based on the vibro-acoustic signal from the knock sensor and the signal from the pressure sensor glow plug (PSG). The reason the authors decided to discuss the issue is increasing interest in the use of information contained in the generated vibration and acoustic emissions as well as reducing acoustic emissions as one of the environmental threats. The adopted form of experiment and analysis enables determining the validity of testing of NVH multifuel engines. Information based on the vibro-acoustic signal allows to determine the qualitative and quantitative occurrence of the phenomenon of knocking in case of proper analysis. Both the energy spectrum of the vibration and the summation value of the successive bands of the spectrum confirm the occurrence of knock resulting from the analysis of the pressure in the combustion chamber and allow to relate to its intensity.
\end{abstract}

Keywords: knock, dual fuel, LPG, vibration.

\section{Nomenclature}

NVH Noise, vibration, and harshness

LPG Liquefied petroleum gas

SOI Start of injection

CI Compression engine

PSG Pressure sensor glow plug

B\&K Bruel and Kjaer

NI National instruments

IAT Intake air temperature

EGT Exhaust gas temperature

$f \quad$ Frequency

RPM Revolutions per minute

$\mathrm{AF} / \mathrm{R} \quad$ Air fuel ratio

$\lambda \quad$ Lambda coefficient

\section{Introduction}

Referring to the famous quote usually attributed to Saudi oil minister Sheik Ahmed Zaki Yamani in the 2005 New York Times article "The Breaking Point" - "he Stone Age didn't end for lack of stone, and the oil age will end long before the world runs out of oil" suggests that particular attention should be drawn to development of control systems, and thus the accompanying possibility of improvement in the employed processes, including the fuel combustion process, as well as the administrative-legal changes, with special focus on the norms regarding pollution in relation to vehicle drive systems [1].

Development of electronic control systems achieved in recent years in automotive industry allows for yet another approach towards the topic of dual fuel powering of engines with 
compression-ignition. Applying dual fuel powering enables using different parameters of fuels in order to optimise the process $[2,3]$. The amount of information reaching the engine controllers and the time needed to process it provides opportunities to move the barriers which limited the participation of alternative fuels used to power compression-ignition (CI) engines. In recent years in Central Europe, a growing interest in LPG injection installations for CI engines can be observed. This results from the low price of this fuel, wide distribution network, and a relatively cheap way of storage and transport [4].

LPG is a liquid fuel used mainly as a replacement for a regular fuel for engines with spark ignition. For the last few years, the tests have been conducted related to effects of the LPG addition to the engines with compression-ignition [5-8]. It results from the attempts to replace a part of a diesel oil dose with a cheaper fuel, in order to cause the cost reduction without simultaneous loss of the performance parameters.

Even though significant physicochemical differences of both fuels allow for their use in optimisation of the compression process, unfortunately, they also induce design problems during simultaneous powering of the combustion engine. Diesel oil has a property of self-ignition, thus being an initiator of the combustion process. LPG, however, is a gaseous fuel characterised with susceptibility to the phenomenon of knocking combustion, which is disadvantageous during combustion of such a mixture. A high compression ratio causes an increase in the probability of occurrence of this phenomenon as a result of high temperature at the end of the compression phase $[9,10]$. Its occurrence was investigated scrupulously at Kazimierz Pulaski University of Technology and Humanities in Radom $[11,12]$. The phenomenon of knocking combustion has a degenerative effect on engine parts [13], causing their permanent damage.

The commercial control systems of LPG injection installations in CI engines are based to a large extent on the low amount of information about the current parameters of the engine operation [14]. Reduction or turning off the LPG addition takes place as a result of exceeding a specific temperature of exhaust gases or when the information comes from the additional sensor of knocking combustion. Based on little amount of information, it is difficult to adjust the maximal participation of LPG that will not induce the knocking combustion phenomenon.

Within the framework of the research conducted by the team of authors, an attempt has been made to identify the occurrence of knocking combustion, based on information from a vibroacoustic signal from the knock sensor, and a signal from the pressure sensor in the type PSG glow plug. The reason why the authors discuss this subject is the growing interest in using the information included in generated vibrations and in the acoustic emission $[15,16]$ as well as in the reduction of the acoustic emission as one of the environmental threats. Another emission of vibrations and noise in a dual fuel engine is generated by the pressure change in the combustion chamber, which correlates with the measured parameters, among others, the torque. This phenomenon seems to be interesting if an attempt to optimise the selected control parameters is taken into consideration, where the optimisation criterion is avoiding the occurrence of the knocking combustion, and reduction of vibrations.

\section{Testing stand and measurement methods}

The testing stand, where the tests mentioned below were carried out, is a SEAT Cordoba 6L vehicle, equipped with the modified dual fuel engine based on the unit marked 1.4 TDI AMF.

The engine of the tested vehicle was adapted to the dual fuel operation by means of employing an additional LPG installation with injectors located in the intake manifold tubes. The gas is injected sequentially, supplying all cylinders one by one. Additionally, the compression ratio was decreased to the value of 18.5, by using a thicker gasket and increasing the space of the combustion chamber by means of sleeves for the installation of the glow plugs with the pressure sensor (Fig. 1). The used glow plugs required employing the sleeves constituting the connection between different threads in the cylinder head and spark plug. The method and place of installation of the mentioned elements are shown in Fig. 1. Additionally, a series of sensors were installed, 
measuring the values described in the further part of this chapter.

The tests were conducted during operation with the constant load and the constant rotational velocity, on the chassis dynamometer at the Automotive Industry Institute. During the tests, the head vibrations (the B\&K and knock sensors) were registered among other parameters, the $\lambda$ ratio, the air temperature in the intake and exhaust manifolds, fuel doses, amount of air, pressure in the intake manifold, pressure inside the combustion chamber (PSG), rotational velocity, engine load, torque, and many other parameters, which are discussed in other articles. During the tests, the LabVIEW environment was used to register all measured signals. For the registration of noise, the acoustic pressure sensor was used (B\&K 4958 type), whereas for the registration of vibrations a three-axis vibration sensor (B\&K, 4504 type), the method and place of installation of which are shown in Fig. 2, and a commercial Bosch 0261231146 knock sensor. As follows from the figure, the place of installation of both sensors was chosen so as to minimise the interferences of the registered signals by the operating engine assemblies. The signals were sampled with the frequency of $51.2 \mathrm{kHz}$, and every measurement lasted 5 seconds. The NI 9234 measurement cards were used for the measurements. The load shown in the diagrams is understood as a percentage of the maximal torque generated for a given rotational velocity.

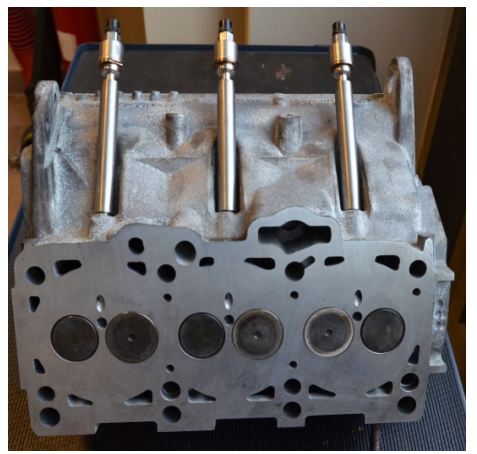

Fig. 1. Glow plug (PSG) mounting sleeves

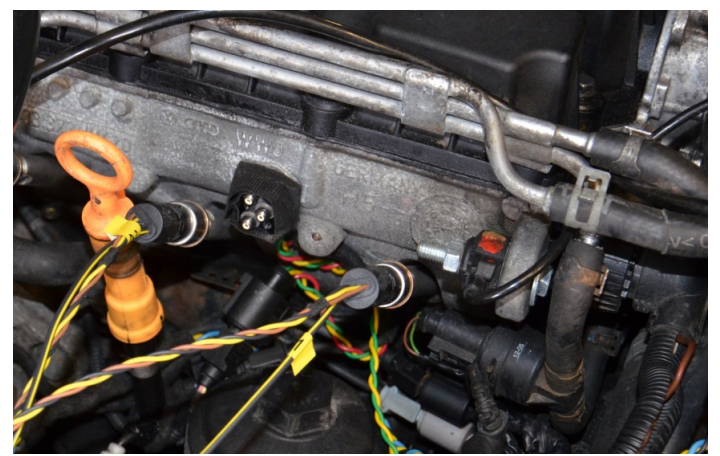

Fig. 2. Installation of sensors: a combustion knock sensor and a three-axis acceleration sensor

\section{Analysis of results}

In order to analyse the occurrence of knocking combustion in a dual fuel CI engine, the registered vibration signals were subjected to Fourier transform, resulting in obtaining a series of amplitude spectra. They enabled observation of the vibration value for specific frequencies, with particular focus on the band correlated with the band from the (commercial) knock sensor.

In the first step, the amplitude spectra were analysed for the whole range of investigated frequencies. Spectra were generated for 3 rotational velocity values, i.e.: 1500, 2000, and 2500 RPM for different LPG shares with the constant load of $70 \%$ of the moment generated for a given rotational velocity (Fig. 3 ).

The diagrams shown above (Fig. 4, 5) indicate a significant increase in vibration amplitude in the band correlated with knocking combustion. It is particularly evident for the velocity values of 2000 and 2500 RPM in the case of greater LPG shares - of $30 \%$ and $40 \%$. The tests were conducted for different loads too, where the results were convergent. Rotational velocity of 2500 RPM was selected as the value for which the further analyses will be performed, because at this velocity the engine generates the biggest torque and the occurrence of knocking combustion can have potentially the most acute degradation effects. The level of vibration amplitude for this velocity value in the case of high LPG shares suggests the occurrence of rapid pressure changes in the combustion chamber which can indicate the occurrence of the knocking combustion phenomenon. In order to provide a better illustration of the occurrence of this phenomenon, amplitude spectra of the vibration energy were created, where energy is understood as the product 
of the amplitude and frequency squares. The plots of different engine loads are shown below, with the $30 \%$ LPG share (Fig. 6) and $40 \%$ LPG share (Fig. 7).

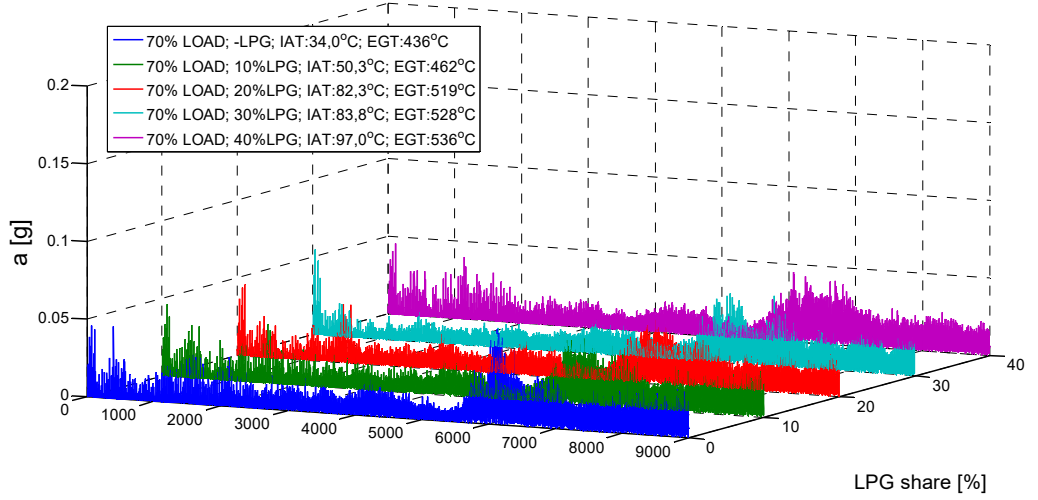

$\mathrm{f}[\mathrm{Hz}]$

Fig. 3. Amplitude spectrum, 1500 RPM, $70 \%$ load, LPG share (0-40 \%)

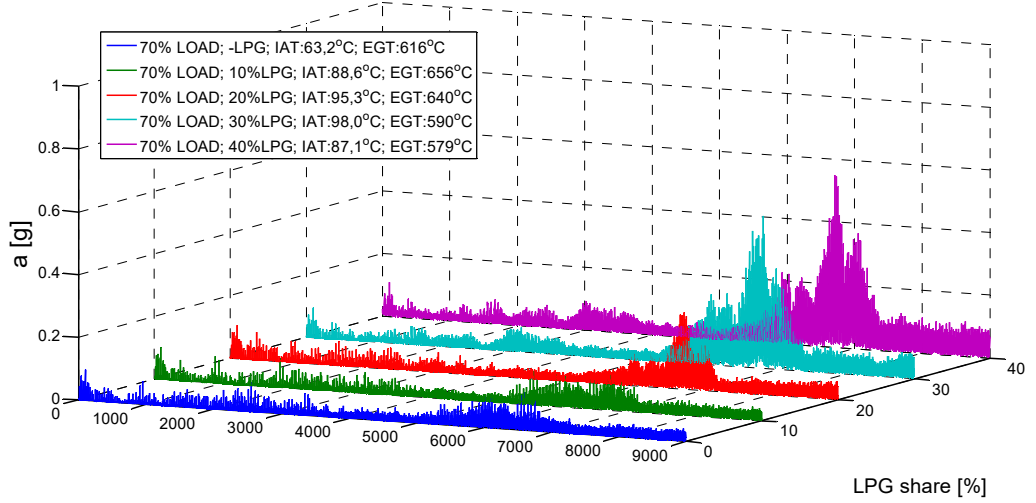

$\mathrm{f}[\mathrm{Hz}]$

Fig. 4. Amplitude spectrum, 2000 RPM, $70 \%$ load, LPG share (0-40 \%)

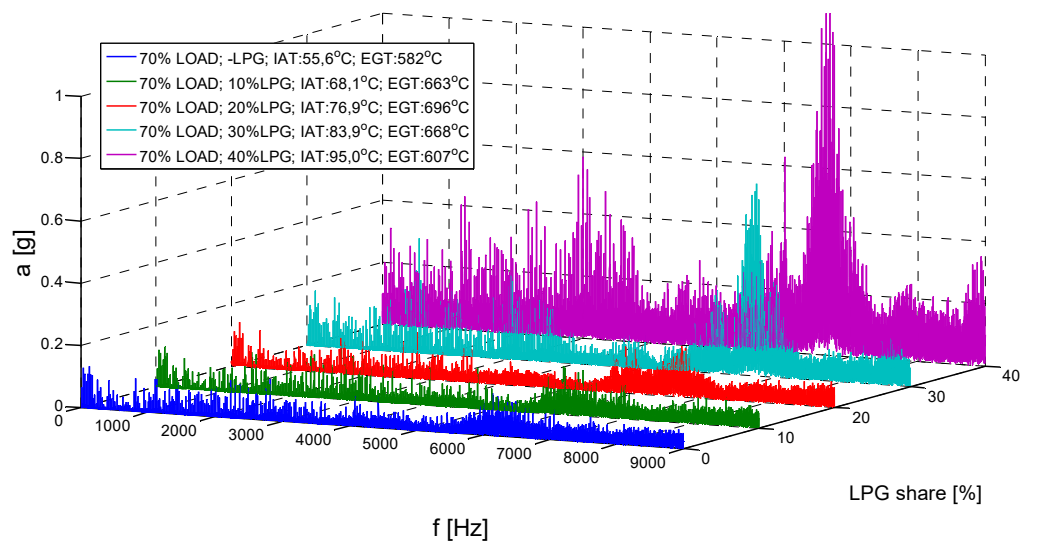

Fig. 5. Amplitude spectrum, 2500 RPM, $70 \%$ load, LPG share (0-40\%)

As can be observed in the presented charts (Fig. 6, 7), for the loads of over $50 \%$ of the generated maximal torque for a given rotational velocity, vibration energy assumes far greater values. In the light of the results presented above, it can be indicated that greater LPG share and 
greater load cause the increase in probability of the occurence of knocking combustion and thus further analyses were conducted for these parameters.

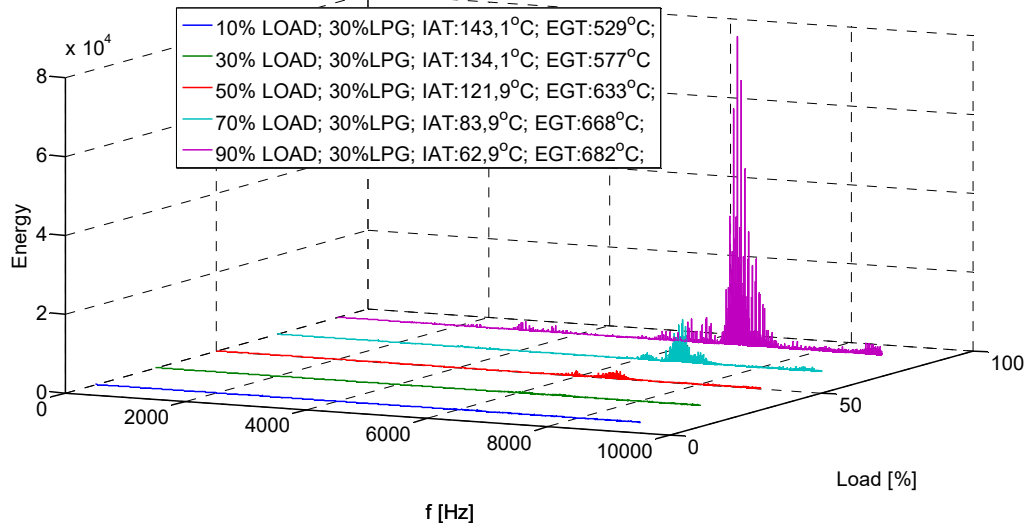

Fig. 6. Energy spectrum, 2500 RPM, 30 \% LPG, load share (10-90 \%)

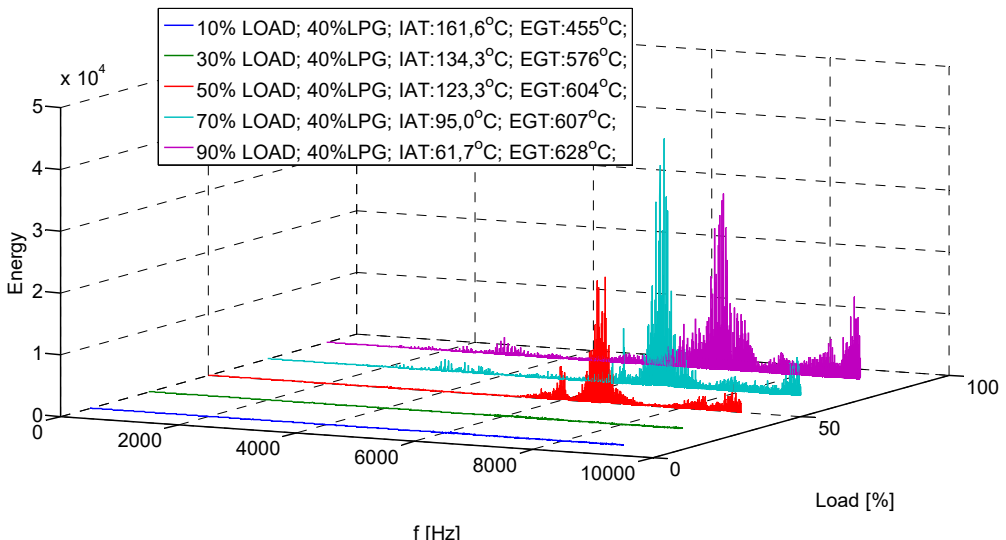

Fig. 7. Energy spectrum, 2500 RPM, $40 \%$ LPG, load share (10-90 \%)

Observing the whole spectrum allows to observe certain tendencies, however, it is more difficult to read or evaluate specific values that would provide any comparable measure. Therefore, the next step was determining an index, that would be easy to interpret using the presented results. The area under the spectrum was used as such an index, determined for subsequent frequencies. The results of these operations are shown in Fig. 8 and 9.

The Figs. 8 and 9 shows total signal energy, calculated as a sum of energy values of the subsequent harmonic components (lines), taking into account the defined number of lines.

The diagram unequivocally demonstrates the frequency range within which energy increase is the biggest and indicates the occurrence of knocking combustion. For the range of $6.5-7 \mathrm{kHz}$ the energy increase by several times can be observed, whereas the final value is several times higher. This frequency range also corresponds to the calculations originating from the frequency formula related to occurrence of vibrations resulting from knocking combustion:

$f_{k}=\frac{900}{3,14 x R^{\prime}}$

where $f_{k}$ - the resonant frequency, $R$ - the cylinder radius.

The above relationship was developed for the spark-ignition engines, where the conditions in 
the combustion chamber differ to a large extent from those in compression-ignition engines. Thus, taking into consideration higher pressure values in the combustion chamber and the corresponding higher temperatures, greater velocity values of the wave propagation can be expected, and hence higher vibration frequencies. In order to use the presented measure with the unambiguous determination of the occurrence of knocking combustion, diagrams were generated with pressure curves in the combustion chamber, where pressure was measured by means of using the PSG type glow plugs with the pressure sensor built in. These diagrams were averaged on the basis of a hundred subsequent cycles of the engine work in a given measurement session.

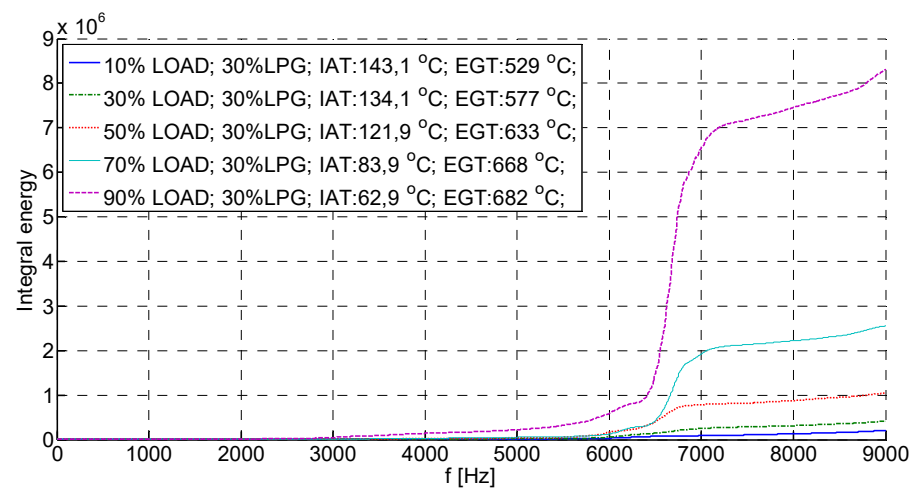

Fig. 8. Integral energy, 2500 RPM, 30 \% LPG, load share (10-90 \%)

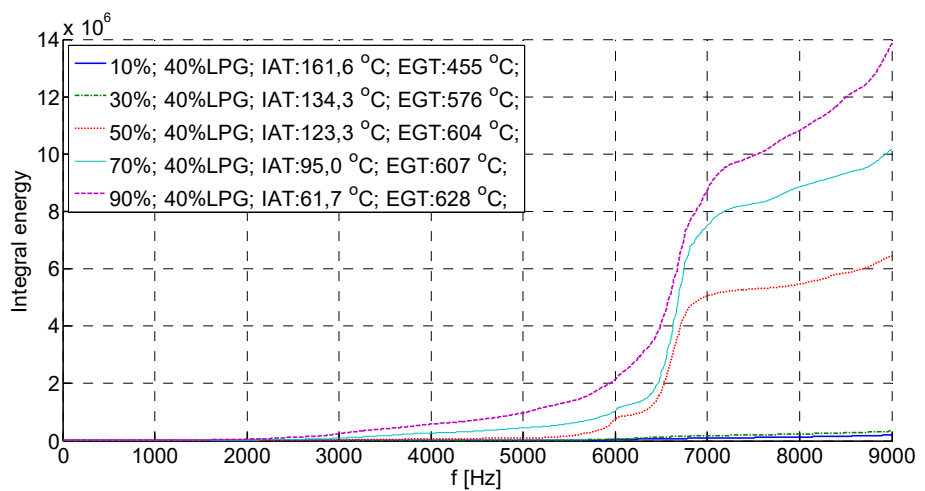

Fig. 9. Integral energy, 2500 RPM, 40 \% LPG, load share (10-90\%)

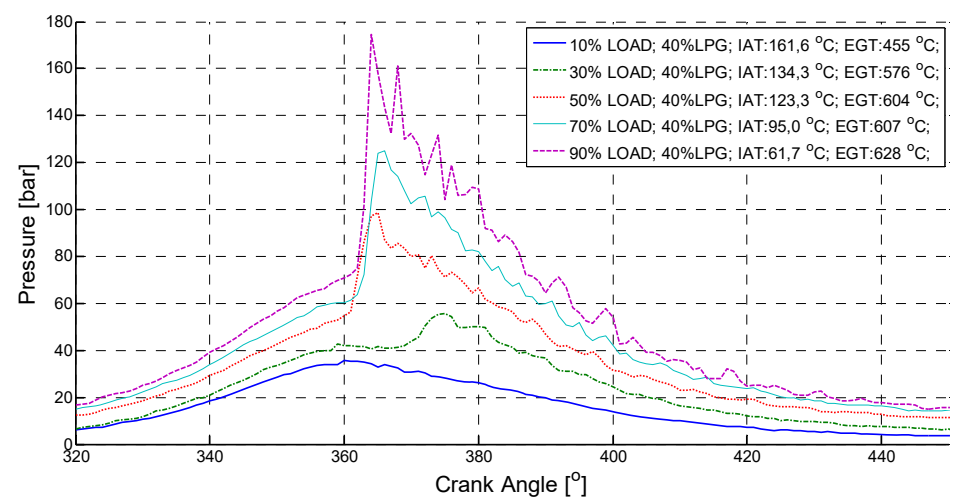

Fig. 10. Pressure in the combustion chamber, 2500 RPM, $40 \%$ LPG, load share (10-90 \%)

Observing the diagrams shown above makes it possible noticing the pressure oscillations after 
the mixture explosion as well as pressure increase related to it. Based on information shown in [11], knocking combustion takes place along the pressure change greater than $0.3 \mathrm{MPa} / \mathrm{CA}$. Therefore, the pressure curves were differentiated and the diagrams were plotted (Fig. 11). In order to evaluate the legitimacy of this thesis, the diagram of a zero LPG share was generated in the first place, which will serve as a reference for the remaining diagrams and will enable evaluation of the maximal pressure increase with the powering with diesel oil only. The presented results suggest that the maximal pressure increase without the occurrence of knocking combustion can reach the value at the level of $0.5 \mathrm{MPa} / \mathrm{CA}$.

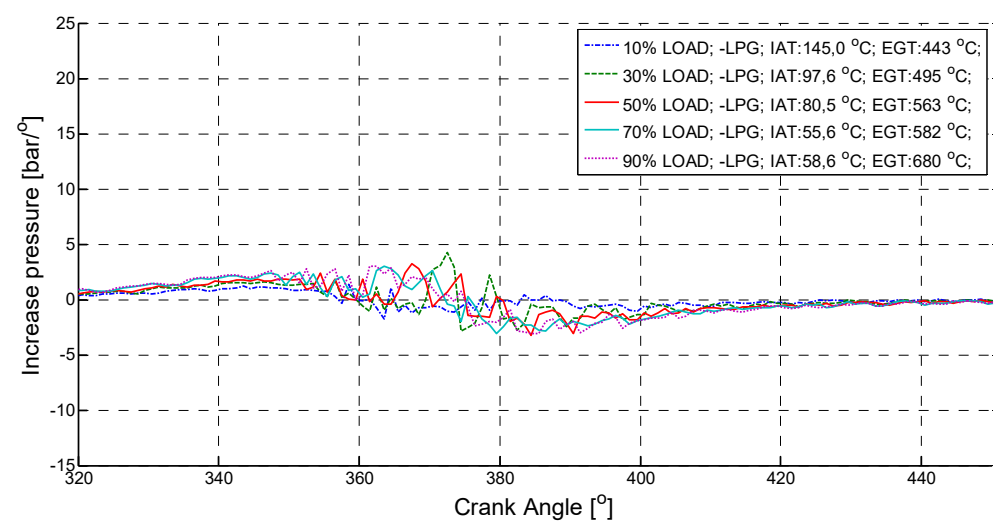

Fig. 11. The increase in pressure in the combustion chamber, 2500 RPM, $0 \%$ LPG, load share (10-90\%)

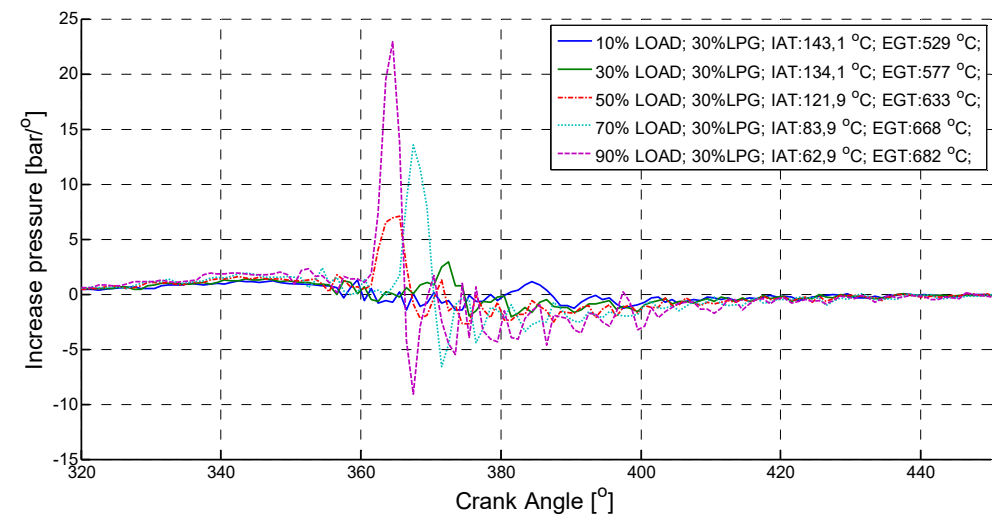

Fig. 12. The increase in pressure in the combustion chamber, 2500 RPM, $30 \%$ LPG, load share (10-90 \%)

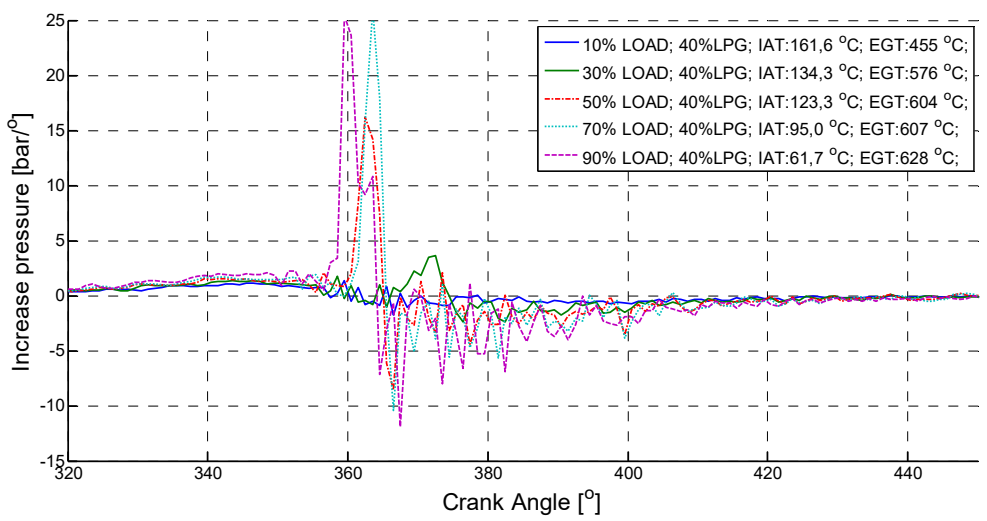

Fig. 13. The increase in pressure in the combustion chamber, $2500 \mathrm{RPM}, 40 \% \mathrm{LPG}$, load share (10-90\%) 
The representation of data shown above (Fig. 12,13) indicates unequivocally the occurrence of knocking combustion phenomena because of the fact of the direct reading of the pressure increase. For the loads greater than $50 \%$, the pressure increase exceeds the value of $0.5 \mathrm{MPa} / \mathrm{CA}$.

\section{Conclusions}

The adopted form of experiment and analysis allows for indicating legitimacy of the vibroacoustic investigations on multi-fuel engines. The information from the vibroacoustic signal allows for qualitative but also quantitative determination of the knocking combustion phenomenon, in situation when it is properly analysed. The obtained information can be used in the control and diagnostic systems applied in engines which are powered by various fuels of different qualities. Such an approach enables control of the way pressure increases during the process of fuel combustion in the combustion chamber, which translates into generating the torque. Both the spectrum of the vibration energy and the sum of the values of the subsequent spectral lines prove the occurrence of the knocking combustion phenomenon resulting from the analysis of the pressure curve in the combustion chamber, and also allow to refer to its intensity. Information processed properly by the control system enables reduction of the LPG addition with its simultaneous maximal share, not resulting in knocking combustion. Possibility of maximising the LPG share improves the economical condition underlying the use of gaseous fuels in powering the compression ignition engines. Further development of this approach may enable control of velocity of the increase in combustion pressure in real time, which will directly influence the way the pressure energy is changed into mechanical energy of the piston motion.

\section{References}

[1] Regulation (EC) No 715/2007 of the European Parliament and of the Council of 20 June 2007 on Type Approval of Motor Vehicles with Respect to Emissions from Light Passenger and Commercial Vehicles (Euro 5 and Euro 6) and on Access to Vehicle Repair and Maintenance Information.

[2] Ambrozik A., Orliński P., Orliński S. Influence of diesel engine fuelling with different fuels on self-ignation delay in aspect of ecology. Eksploatacja i Niezawodność - Maintenance and Reliability, Vol. 19, Issue 3, 2003, p. 50-55.

[3] Kruczyński B. S. W., Orliński P., Wojs M. K., Owczuk M. Assess the possibility of using biogas for combustion in a compression ignition engine with diesel fuel piloting dose. Zeszyty Naukowe Instytutu Pojazdów, Vol. 100, Issue 4, 2014, p. 103-111.

[4] Raslavicius L., Kersys A., Mockus S., Kersiene N., Starevicius M. Liquefied petroleum gas (LPG) as a medium-term option in the transition to sustainable fuels and transport. Renewable and Sustainable Energy Reviews, Vol. 32, 2014, p. 513-525.

[5] Tira H. S., Herreros J. M., Tsolakis A., Wyszynski M. L. Characteristics of LPG-diesel dual fuelled engine operated rapeseed methyl ester and gas-to-liquid diesel fuels. Energy, Vol. 47, 2012, p. 620-629.

[6] Wagemakers A. M. L. M., Leermakers C. A. J. Review on the effects of dual fuel operation, using diesel and gaseous fuels, on emissions and performance. SAE, 2012.

[7] Murthy K., Madhwesh N., Shrinivasa Rao B. R. Influence of injection timing on the performance of dual fuel compression ignition engine with exhaust gas recirculation. International Journal of Engineering Research and Development, Vol. 11, 2012, p. 37-42.

[8] Mikulski M., Wierzbicki S., Piętak A. Numerical studies on controlling gaseous fuel combustion by managing the combustion process of diesel pilot dose in a dual fuel engine. Chemical and Process Engineering Vol. 36, Issue 2, 2015, p. 225-238.

[9] Li Ma Xiao, Qi Yanfei, Xu Yunliang, Shijin Hongming Shuai Optical study of throttleless and EGR-controlled stoichiometric dual fuel compression ignition combustion. Fuel, Vol. 182, 2016, p. $272-283$.

[10] Hosseinzadeh A., Khoshbakhtisaray R. Comparison of thermal, radical and chemical effects of EGR gases using availability analysis in dual fuel engines at part loads. Energy Conversion and Management, Vol. 51, Issue 11, 2010, p. 2321-2329. 
[11] Różycki A. Opportunity of application of the knock phenomenon and smoke emission for the control of common-rail injection parameters. Combustion Engines, Vol. 162, Issue 3, 2015, p. 1046-1052.

[12] Różycki A. Granica Spalania Stukowego w Dwupaliwowym Silniku o Zapłonie Samoczynnym. Czasopismo Techniczne Mechanika, Wydawnictwo Politechniki Krakowskiej z., 2008, p. 129-137.

[13] Mohsen M. Abdelaal, Basem A. Rabee, Abdelrahman Hegab H. Effect of adding oxygen to the intake air on a dual fuel engine performance, emissions, and knock tendency. Energy, Vol. 61, 2013, p. 612-620.

[14] Walczak D., Zieliński L., Szczurowski K., Radkowski S. Proposed methods of controlling dual fuel CI engine using CAN-BUS information. Dynamical Systems, Mechatronics and Life Sciences, 2015, p. 543-554.

[15] Radkowski S. Use of vibroacoustical signal in detecting early stages of failures. Eksploatacja i Niezawodnosc-Maintenance and Reliability, Vol. 35, Issue 3, 2007, p. 11-18.

[16] Burdzik R., Konieczny L., Figlus T. Concept of on-board comfort vibration monitoring system for vehicles. Activities of Transport Telematics, Communications in Computer and Information Science, Springer, Heidelberg, 2013, p. 418-425.

[17] Chung Chang Chih, Lo Jiunn Guang, Wang Jia Lin Assessment of reducing ozone forming potential for vehicles using liquefied petroleum gas as an alternative fuel. Atmospheric Environment, Vol. 35, 2001, p. 6201-6211.

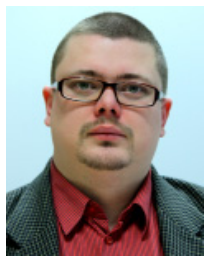

Doc. Eng. Krzysztof Szczurowski, Ph.D. is a postdoctoral manager at Integrated Laboratory of Mechatronics System of Vehicles and Construction Machinery of Warsaw University of Technology. His scientific interests include computational mechanics, sound and vibration and mechatronics.

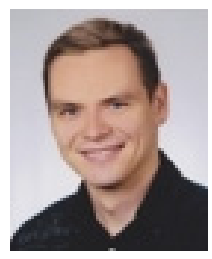

Lukasz Kurkus, Ph.D. student in Integrated Laboratory of Mechatronics System of Vehicles and Construction Machinery of Warsaw University of Technology. His research interest comprise mechanics, free piston engine, control algorithms.

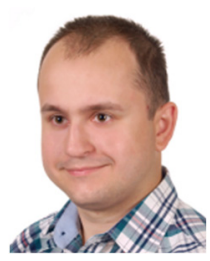

Damian Walczak, Ph.D. student in Integrated Laboratory of Mechatronics System of Vehicles and Construction Machinery of Warsaw University of Technology. His research interest is focused on the electronic engine control systems.

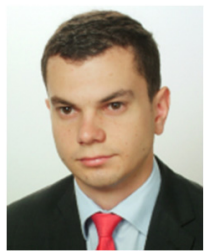

Lukasz Zieliński, Ph.D. student in Integrated Laboratory of Mechatronics System of Vehicles and Construction Machinery of Warsaw University of Technology. His research interest is focused on control of combustion engine and alternative fuels. 